\title{
Study on the Simulation of AC Permanent Magnet Synchronous Motor Servo System
}

\author{
Caihong Zhu, Hongtao Zhang and Yongjian Zhao \\ Suzhou Vocational University, Suzhou, Jiangsu, China \\ zhuzhang_2000@163.com
}

\begin{abstract}
Keywords: Permanent Magnetic Synchronous Motor; Vector Control; Simulation Model
Abstract. Based on the analysis of theories of vector control, the simulation model of permanent magnet AC servo system built on MATLAB/SIMULINK is designed and studied, the simulation results prove the validity of the simulation model.
\end{abstract}

\section{Introduction}

Simulation is an important means of system analysis, which can verify the correctness of the theoretical analysis and design, simulate the operation process of the actual system, analyze the system characteristics changing with the parameters, describe the status and characteristics of the system, explore the design results how to meet the practical requirements, also can discuss the stability of the system, study the influence on the system dynamic performance of the system control parameters and the load change, and study the control methods and means to improve the performance of the system. The simulation has the same effect as the experiment, and can avoid the complexity of the actual experiments, and complete the simulation of experiment system or process, which cannot be done on the actual experiment. There is a number of factors affecting the operation of the servo system. How to find the optimal control parameters and adopt proper means of control in the complicated environmental conditions, is the need to further discuss on the design and operation of the servo system, and these factors will affect the operation of the actual system and its adaptability to the environment.

The simulation model based on Matlab software is created according to the actual composition of the permanent magnet synchronous servo system. The system simulation is carried in the Simulink environment. The simulation results is need to be analyzed in order to find the system control rule, optimize the system control method, analyze the operation characteristic of system, and design, adjust and operate the system.

\section{Vector Control Principle}

Vector control principle is said that the stator current vector of the magnetic field orientation control is decomposed into two components: the excitation current component id and the torque current component id, and the two components are perpendicular to each other, independent of each other, and then adjusted respectively, and can be obtained good decoupling control features.

The basic block diagram of the permanent magnet synchronous motor vector control system is shown in Figure 1. First, the rotor position can be detected by the encoder, and converted to the rotational speed $\omega_{\mathrm{r}}$, the given rotational speed $\omega_{\mathrm{r}}{ }^{*}$ and the deviation of the feedback rotational speed $\omega_{\mathrm{r}}$, then the stator current reference input can be obtained by the speed PI regulator. The stator phase current $i_{a}$ and $i_{b}$ can be extracted through the phase current detection circuit, and then, can be transferred to $\mathrm{d}$, q rotating coordinate system by Clarke and Park. The $i_{\mathrm{d}}{ }^{*}=0$, the ideal control volume can be obtain by the current PI controller, through comparing the current signals of the $d, q$ coordinate system and their reference current input $i_{\mathrm{d}}{ }^{*}$ and $i_{q}{ }^{*}$. The control signals form a complete speed FOC double closed loop system through the Park inverse transformation, 6 PWM signals which are generated from the SVPWM and the speed and torque by the inverter control motor. 


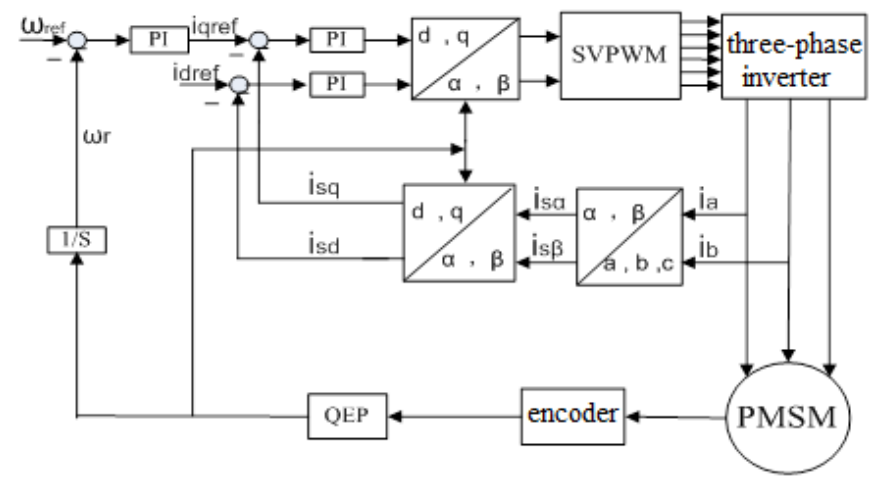

Fig. 1 vector control system block diagram

\section{Establishment of Simulation Model}

Coordinate Transformation Module. There are number of coordinate transformations used in vector control: Clark transformation, Park transform and Park inverse transformation, the transformation matrices are as follows:

Clark transformation: $\quad\left[\begin{array}{l}i_{\alpha} \\ i_{\beta}\end{array}\right]=\sqrt{\frac{2}{3}}\left[\begin{array}{ccc}1 & -\frac{1}{2} & -\frac{1}{2} \\ 0 & \frac{\sqrt{3}}{2} & -\frac{\sqrt{3}}{2}\end{array}\right]\left[\begin{array}{l}i_{a} \\ i_{b} \\ i_{c}\end{array}\right]$

Park transformation: $\quad\left[\begin{array}{l}i_{d} \\ i_{q}\end{array}\right]=\left[\begin{array}{rr}\cos \theta & \sin \theta \\ -\sin \theta & \cos \theta\end{array}\right]\left[\begin{array}{l}i_{\alpha} \\ i_{\beta}\end{array}\right]$

Park transformation: $\quad\left[\begin{array}{l}i_{\alpha} \\ i_{\beta}\end{array}\right]=\left[\begin{array}{rr}\cos \theta & -\sin \theta \\ \sin \theta & \cos \theta\end{array}\right]\left[\begin{array}{l}i_{d} \\ i_{q}\end{array}\right]$

According to the transformation matrix, simulation model can be set up, the dq/abc transformation model is shown in Figure 2.

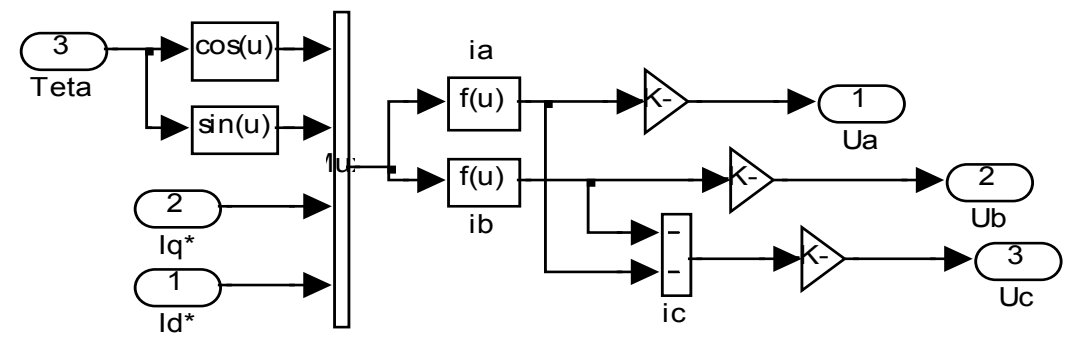

Fig. 2 dq/abc transformation model

SVPWM Generation Module. SVPWM is from motor's perspective, focusing on how to make the motor for constant amplitude round rotating magnetic field, which is the sinusoidal magnetic flux. It takes the ideal magnetic flux circle of the AC motor with balanced three-phase sine voltage power supply mode as a benchmark. It simulates the actual flux generated by the different switch inverter model to benchmark flux circle. It form a PWM waveform by comparing the results of the decision inverter switch state. The number of vector inverter produces is limited, the space vector with continuous changes angle cannot be produced. The generation method of SVPWM is the two adjacent effective vector and zero vector of the eight basic space vector. According to their different respective duration, the space voltage vector $V_{\text {out }}$ is an equivalent vector of the motor. The space voltage vector map is shown in Figure 3. 


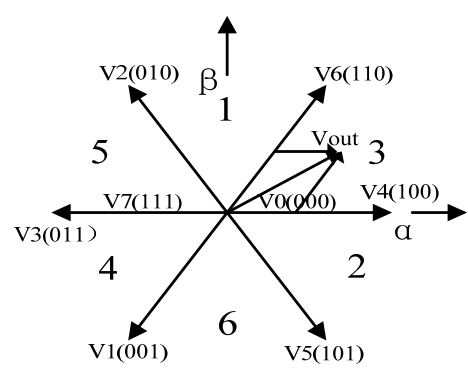

Fig. 3 space voltage vector map

Inverter and Motor Model. Inverter and the permanent magnet synchronous motor model used in the simulation are given in the Simpowersystem of Matlab/Simulink model. The output parameters of the motor inside the motor measurement module of the Simpowersystem in Matlab/Simulink can be directly detected as the feedback parameters of the closed loop system of motor control.

Closed Loop Control System Model of PMSM Vector Control. Connecting each module and the model to constitute the system simulation model, which is shown in figure 4.

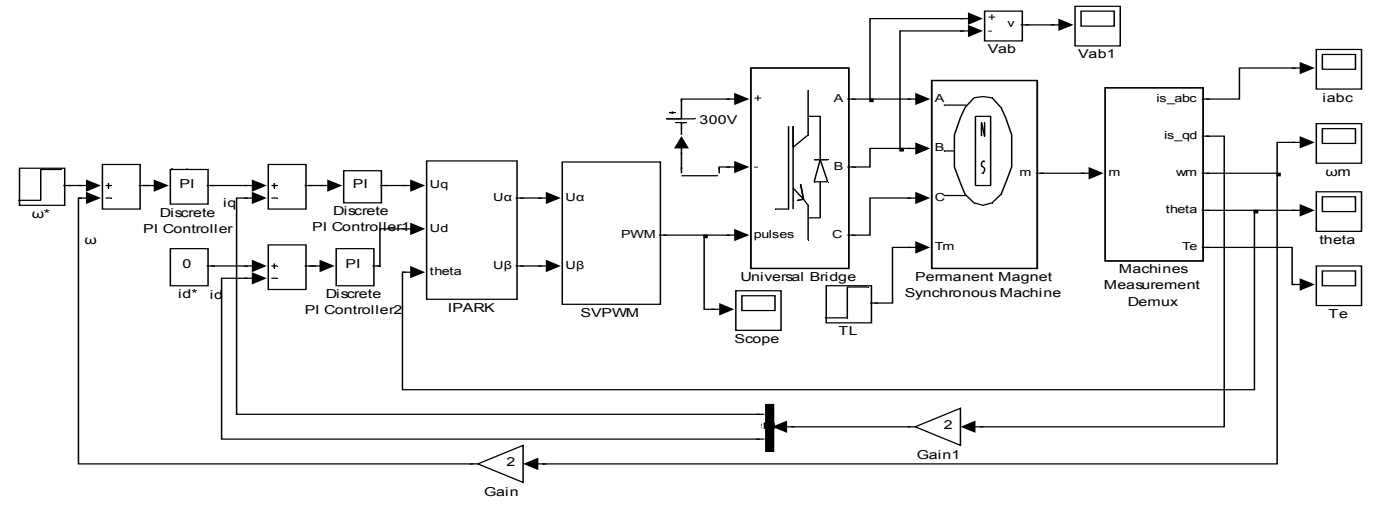

Fig. 4 closed loop control system model of PMSM vector control

\section{Results of Simulation}

In order to verify the correctness of the simulation model and effectiveness, the simulation test is carried on. The selection algorithm of the simulation parameters is discrete algorithm, step length. The parameters in the simulation test motor are: $\mathrm{U}_{\mathrm{DC}}=300 \mathrm{~V} ; \mathrm{n}_{\mathrm{p}}=2 ; \mathrm{J}=0.0003 \mathrm{~kg} \cdot \mathrm{m}^{2} ; \psi_{\mathrm{f}}=0.175 \mathrm{~Wb}$; $\mathrm{R}=1.4 \Omega$. The given speed of the system is $30 \mathrm{r} / \mathrm{s}$, switching frequency is $2 \mathrm{kHz}$, and the simulation results is shown in figure 5 .

The speed simulation waveform and the line voltage simulation waveform for no-load startup are respectively shown in Figure 5 and Figure 6. The given speed is $30 \mathrm{r} / \mathrm{s}$, the actual speed shown in Figure 5 is almost no oscillation and small overshoot in the process of start, and can quickly achieve a given value of $30 \mathrm{r} / \mathrm{s}$. The line voltage shown in Figure 6 is small jitter, but basically stable in the process of start. The stator three phase current simulation waveform of the motor load torque for $1 \mathrm{~N} \cdot \mathrm{m}$ is shown in Figure 7. The torque simulation waveform from 1 to $10 \mathrm{~N} \cdot \mathrm{m}$ for the load torque on $0.5 \mathrm{~s}$ is shown in Figure 8.

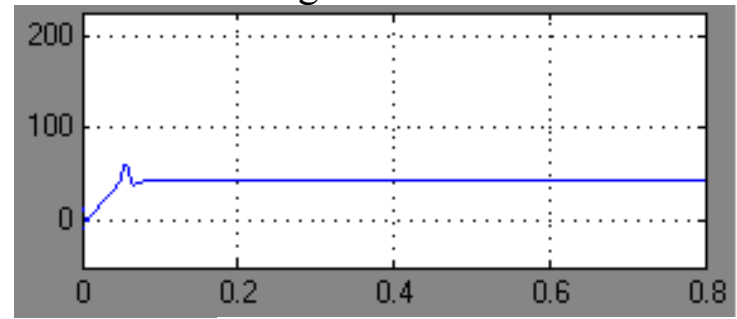

Fig. 5 speed waveform

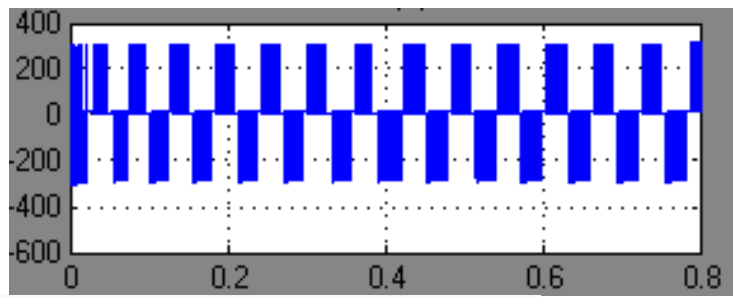

Fig. 6 line voltage waveform 


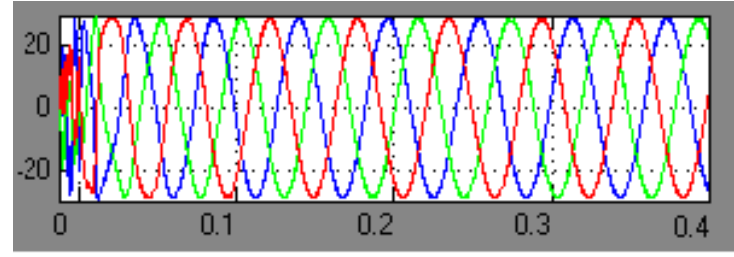

Fig. 7 three phase current waveform of stator

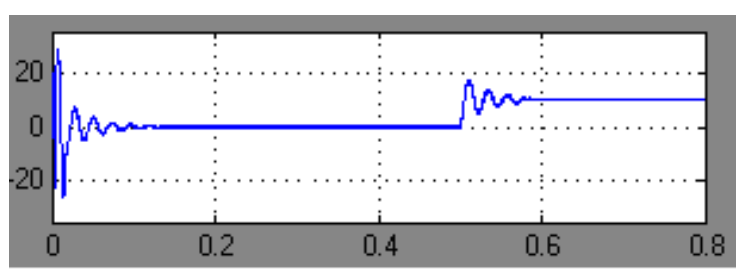

Fig. 8 torque waveform

\section{Conclusion}

The simulation results conform to the operating characteristics of permanent magnet synchronous motor seen from the results of simulation, SVPWM algorithm and built system model are correct. In this paper, the author's innovative is that the magnetic field orientation control in the field of ac motor speed control has a major development is proved theoretically through the theoretical analysis and vector control research of PMSM speed control. The simulation research based on a $2.5 \mathrm{kw} \mathrm{AC}$ permanent magnet synchronous servo motor, fully verified the reliability and practicability of the theory of design, and laid a good foundation for practical application.

\section{Acknowledgements}

At the point of finishing this thesis, I'd like to express my sincere thanks to all those who have lent me hands in the course of my writing this thesis.

\section{References}

[1] Jiai He, Huiqin Wang. System Simulation of Permanent Magnet Synchronous Motor Space Vector Control [J]. Journal of Electric Power System and Automation, 6,014(2005), p. 247

[2] Yongpiao Liu, Yanru Zhong. Vector Control Simulation of Permanent Magnet AC Servo System [J]. Electric Drive Automation, 28(2006), P. 18-21

[3] Yinquan Hu, Wencui Yi. PMSM Speed Control System Based on DSP Design [J]. Microcomputer Information, (2008), P. 52

[4] Rong Chen, Yangguang Yan. Study on Control Strategy of AC Permanent Magnet Servo System [J]. Journal of Electrical and Control, 8, 3(2004), p. 205

[5] Liu Ruifang, Yan Dengjun, Hu Minqiang. Field circuit and movement coupled time stepping finite element analysis on permanent magnet brushless DC motors [J]. Proceedings of the CSEE, 27(2007), p. 59-64

[6] Dong $\mathrm{Xu}$, Jingmeng Liu. Research on key technology of simulation of permanent magnet synchronous motor servo system [J]. Experimental Technology and Management, 29, 4(2012), p.321-325 